\title{
Eastern equine encephalitis and use of IV immunoglobulin therapy and high-dose steroids
}

Douglas R. Wilcox, MD, PhD, * Sarah I. Collens, BS,* Isaac H. Solomon, MD, PhD, Farrah J. Mateen, MD, PhD, and Shibani S. Mukerji, MD, PhD

Neurol Neuroimmunol Neuroinflamm 2021;8:e917. doi:10.1212/NXI.0000000000000917

\section{Abstract}

\section{Objective}

To determine the clinical presentation and patient outcomes after treatment with IV immunoglobulin (IVIG), high-dose steroids, or standard of care alone in Eastern equine encephalitis (EEE), a mosquito-borne viral infection with significant neurologic morbidity and mortality.

\section{Methods}

A retrospective observational study of patients admitted to 2 tertiary academic medical centers in Boston, Massachusetts, with EEE from 2005 to 2019.

\section{Results}

Of 17 patients (median [IQR] age, 63 [36-70] years; 10 (59\%) male, and 16 (94\%) White race), 17 patients had fever (100\%), 15 had encephalopathy $(88 \%)$, and 12 had headache (71\%). Eleven of 14 patients with CSF cell count differential had a neutrophil predominance (mean $=60.6 \%$ of white blood cells) with an elevated protein level (median [IQR], $100 \mathrm{mg} / \mathrm{dL}$ [75-145]). Affected neuroanatomic regions included the basal ganglia $(n=9 / 17)$, thalamus $(n$ $=7 / 17)$, and mesial temporal lobe $(n=7 / 17)$. A total of 11 patients $(65 \%)$ received IVIG; 8 (47\%) received steroids. Of the patients who received IVIG, increased time from hospital admission to IVIG administration correlated with worse long-term disability as assessed by the modified Rankin Scale (mRS) $(r=0.72, p=0.02)$; steroid use was not associated with the mRS score. The mortality was $12 \%$.

\section{Conclusions}

Clinicians should suspect EEE in immunocompetent patients with early subcortical neuroimaging abnormalities and CSF neutrophilic predominance. This study suggests a lower mortality than previously reported, but a high morbidity rate in EEE. IVIG as an adjunctive to standard of care may be considered early during hospitalization.

\author{
Correspondence \\ Dr. Wilcox \\ drwilcox@bwh.harvard.edu
}




\section{Glossary}

AED = antiepileptic drug; EEE = Eastern equine encephalitis; EEEV = EEE virus; IgG $/ \mathbf{M}=$ immunoglobulin G/M; IVIG = IV immunoglobulin; WNV = West Nile virus.

Eastern equine encephalitis (EEE) is a mosquito-borne viral infection that can result in devastating neurologic disease. Although EEE has likely existed for centuries, ${ }^{1}$ the first significant outbreak in humans occurred in $1938^{2}$ Since then, outbreaks have been sporadic, ${ }^{3}$ with an average incidence of 8 cases per year in the United States. ${ }^{4}$ In 2019, there were 37 confirmed cases of EEE in the United States and 12 in Massachusetts, with 15 deaths, making this the largest outbreak since 1959. ${ }^{5}$ EEE virus (EEEV) is one of the most virulent neurotropic viruses with an estimated $40 \%$ mortality rate observed in the past 2 decades. ${ }^{4}$ Outbreaks before 1956 predominantly affected the pediatric population, with $82 \%$ of those infected younger than 18 years. ${ }^{6}$ In contrast, between 2003 and 2016, 63\% of those affected were older than 40 years. ${ }^{4}$

Although the majority of people infected with EEEV are suspected to be asymptomatic, ${ }^{7}$ the clinical presentation of symptomatic adults ${ }^{8}$ and children ${ }^{9}$ is characterized by acute onset of fever, headache, nausea, and encephalopathy with variable presence of meningismus, weakness, and seizure. Long-term outcomes data in EEE are limited to the earlier outbreaks in 1938,1955 , and 1956 with mortality at follow-up at $68 \%{ }^{6}$ Of the survivors, $69 \%$ had paralysis or cognitive impairment, with only $31 \%$ without a significant impairment at follow-up., ${ }^{6,10}$ Longterm outcomes of pediatric EEE cases between 1970 and 2010 similarly demonstrated significant disability in $64 \%$ of survivors at follow-up. ${ }^{9}$ Notably, these survival and follow-up studies were conducted before the regular use of IV immunoglobulin (IVIG) in the treatment of EEE and other arboviral infections. ${ }^{8,11-13}$

There are no specific antiviral treatments for EEE, unlike other viral encephalitides including herpes simplex virus, varicella zoster virus, and cytomegalovirus. ${ }^{14}$ Case reports suggest possible benefit from treatment with IVIG or negative outcomes with high-dose steroids; however, data are limited in EEE. ${ }^{15-18}$ IVIG has been trialed as a treatment for West Nile virus (WNV) encephalitis and other related arboviral infections in small trials with inconclusive results showing no clear benefit on morbidity or mortality. ${ }^{11,12,19,20}$

The clinical, laboratory, and radiographic characteristics of EEE, including treatment with IVIG and high-dose steroids, remain limited. Here, we describe 17 cases of EEE diagnosed in the northeast over the past 15 years, including the most recent major outbreak in 2019. We also provide available data on postdischarge outcomes in patients treated with IVIG or steroids in addition to standard of care.

\section{Methods}

\section{Ethics}

The study protocol was approved by the Partners Healthcare Institutional Review Board of Massachusetts General
Hospital and Brigham and Women's Hospital (Protocol 2019P003215).

\section{Patient identification}

EEE cases were identified by searching the Partners Healthcare Research Patient Data Registry system using the International Classification of Diseases (ICD) 9th and 10th edition diagnostic codes for EEE (ICD-9: 0622 and ICD-10: A83.2). Testing of patients for EEE was based on clinical suspicion for encephalitis per practice guidelines from the Infectious Diseases Society of America. ${ }^{14}$ All patients definitively diagnosed with EEE using the Massachusetts Department of Public Health CSF immunoglobulin M/G (IgM/IgG) diagnostic test (screening enzyme immunoassay [EIA] IgM specific for $\mathrm{EEE}$ and $\mathrm{WNV}){ }^{21}$ with the exception of 1 patient on rituximab diagnosed by CSF EEEV PCR (PCR) targeted to the structural polyprotein coding sequence, performed at the William A. Hinton State Laboratory Institute, Department of Public Health, Boston, MA). Although false-positive and negative rates may vary with individual assays, enzyme-based immunoassays for EEE have been reported to have a falsepositive rate of $5.6 \%$ and a false-negative rate of $0.7 \% .{ }^{22}$ Positive samples were subsequently confirmed by the plaque reduction neutralization test. Patients evaluated at Massachusetts General Hospital or Brigham and Women's Hospital between January 1, 2005, and January 1, 2020, were included in the review.

\section{Data collection and variables}

Data on clinical presentation, laboratory values, MRI and EEG studies, treatment, and outcomes were collected until a censoring date of January 1, 2020, and entered into a central HIPAAcomplaint database (REDCap). Prodromal period was defined as time from onset of symptoms typical for EEE, including fever, altered mental status, and headache, to presentation to the emergency department. The modified Rankin Scale (mRS) ${ }^{23}$ was retrospectively determined by 2 independent neurologists (D.R.W. and S.S.M.) for the time points of presentation, discharge from the hospital, and last known follow-up. Treatment groups were identified by patients who received IVIG or highdose steroids during hospitalization. High doses were defined as greater than $100 \mathrm{mg}$ of prednisone equivalent per day. ${ }^{24,25}$

All available brain MRI studies were reviewed by 3 study neurologists (F.J.M., D.R.W., and S.S.M.), or when unavailable, the radiologist reports were used. Neuroanatomic regions of involvement were determined by abnormal T2FLAIR hyperintensity. Regions of interest were determined a priori based on published reports of EEE. Two study neurologists (D.R.W. and S.S.M) independently reviewed EEG reports. 


\section{Statistical analysis}

All statistical analyses were performed and graphs created using Prism by GraphPad (8) or R software (v. 3.6.1, Vienna, Austria). ${ }^{26}$ Univariate analyses were performed for clinical characteristics and laboratory values with mean averages and SD reported. Comparative studies were performed using a Spearman rho. A $p$ value with a 2 -tailed distribution was calculated with a level of significance set at 0.05 .

\section{Data availability}

Full anonymized data from this study are available on request to any qualified investigator.

\section{Results}

\section{Patient demographics}

The median EEE patient age was 63 years (IQR $=36-70$ years) (table 1) with a bimodal distribution that included 3 pediatric cases and an age range from 8 months to 78 years (figure e-1, links.lww.com/NXI/A348). The cases spanned 5 states in the Northeastern United States (table e-1, links.lww.com/NXI/ A348). Symptom onset occurred between July and September, with the earliest symptom onset July 30 and the latest September 13. The majority $(59 \% ; 10 / 17)$ of cases had symptomatic onset in August, with 35\% of the remaining cases occurring in September. In $76 \%(13 / 17)$ of patients, there was an identifiable outdoor and mosquito exposure before symptom onset, including outdoor work, hiking, camping, or outdoor school activities (table e-1, links.lww.com/NXI/A348). Sixteen patients had no relevant medical history; 1 patient was immunosuppressed with rituximab $\left(\% \mathrm{CD} 19^{+}\right.$cell count $=0$ during hospitalization) as maintenance therapy for non-Hodgkin lymphoma and reported previously. ${ }^{27}$

\section{Clinical presentation}

Patients had fever (100\%, average maximum temperature $39.4^{\circ} \mathrm{C}$ in adults, $39.7^{\circ} \mathrm{C}$ in children), altered mental status (n $=15 ; 88 \%)$, and headache $(\mathrm{n}=12 ; 71 \%)$ (table 1$)$. The average prodromal period from symptom onset to presentation was 3.4 days ( $\mathrm{SD}=3$ days) (figure e-1, links.lww. com/NXI/A348). The prodromal period ranged from 1 patient with rapid progression of symptoms over the course of 1 day to a maximum length of 9 days. In the emergency department, the majority of patients presented with neurologic symptoms, including altered mental status in $88 \%$ and clinical seizures (generalized tonic-clonic episodes) in $41 \%(n=7)$. When analyzed by age group, $100 \%$ of children had seizures at presentation compared with $29 \%$ of adults. Classic signs suggestive of meningitis, including neck stiffness and photophobia, were less common $(n=3,18 \%)$.

\section{Laboratory characteristics}

Serum studies at presentation were characterized by a median leukocytosis of 13,000 cells $/ \mathrm{mL}^{3}$ ( $\mathrm{IQR}=8,000-16,000$ cells $)$, low end of normal sodium levels (median $=135 \mathrm{mmol} / \mathrm{L}, \mathrm{IQR}=$ $133-138 \mathrm{mmol} / \mathrm{L})$, normal platelet counts $($ median $=187,000$ cells $/ \mathrm{mL}^{3}, \mathrm{IQR}=158,000-236,000$ cells $/ \mathrm{mL}^{3}$ ), and normal aspartate transaminase and alanine aminotransferase (table 1). All patients had a lumbar puncture performed within 3 days of presentation. The CSF was characterized by a pleocytosis with a median white blood cell (WBC) count of 369 cells $/ \mathrm{mL}^{3}$ (IQR = $185-831$ cells $\left./ \mathrm{mL}^{3}\right)$ (table 1$)$; the majority $(\mathrm{n}=14 ; 82 \%)$ of CSF samples contained less than $1,000 \mathrm{WBC} / \mathrm{mL}^{3}$ (figure $1 \mathrm{~A}$ ). The median CSF WBC count in the 3 pediatric cases was 324 $\mathrm{WBC} / \mathrm{mL}^{3}$ compared with $680 \mathrm{WBC} / \mathrm{mL}^{3}$ in adults. It is challenging to make definitive comparisons given the small sample size, but consistent with historical data, there is no apparent difference in CSF WBC count between children and adults. ${ }^{9}$ CSF protein was elevated to a median of $100 \mathrm{mg} / \mathrm{dL}(\mathrm{IQR}=$ $75-145 \mathrm{mg} / \mathrm{dL}$ ), and CSF glucose was normal (median $=65$ $\mathrm{mg} / \mathrm{dL}, \mathrm{IQR}=57-78 \mathrm{mg} / \mathrm{dL}$ ) (figure $1, \mathrm{~B}$ and $\mathrm{C}$ ). A total of $79 \%(n=11 / 14$ with differential) of patients had a neutrophilic predominance $(60.6 \%$ of $\mathrm{WBC}, \mathrm{SD}=22.8)$ in their CSF (figure 1D). Two patients had a repeat lumbar puncture within 1-3 days of their initial lumbar puncture and showed a shift to an increased lymphocyte fraction. During admission, $29 \%$ of patients developed myelosuppression with leukopenia $(n=1 ; 6 \%)$, thrombocytopenia $(n=1 ; 6 \%)$, or both $(n=3 ; 18 \%)$.

\section{Imaging studies}

All patients had a brain MRI during admission, and 76\% ( $\mathrm{n}=$ 13) of patients received an MRI within 3 days of presentation. Seventy-one percent of patients $(\mathrm{n}=12)$ had at least 1 additional follow-up MRI during the course of their disease. All patients had an abnormal MRI at presentation with the exception of the immunocompromised patient on rituximab; details of this patient's MRI have been previously reported. ${ }^{15}$ Typical MRI findings included T2-FLAIR hyperintense signal in the bilateral basal ganglia, thalami, and mesial temporal lobes (figure $2 \mathrm{~A}$ ). Figure $2 \mathrm{~B}$ demonstrates representative images of patients with mild (mRS 0-2), moderate (mRS $3-4)$, and severe (mRS 5-6) disability score at discharge. Figure 2C demonstrates a representative T2-FLAIR MRI evolution of an adult case (case 8) over the course of hospitalization. Seven cases had extension of T2-FLAIR hyperintensity into the midbrain and pons (figure 2D), whereas only 1 patient had evidence of meningeal enhancement. In addition to the thalamus, pediatric cases had involvement of the cortex, a feature less commonly observed in adult patients ( $100 \%$ of pediatric cases vs $29 \%$ of adults).

\section{EEG findings}

During hospital admission, all but 1 patient had an EEG performed to evaluate for clinical and subclinical seizures. A total of $41 \%$ of patients with EEE had electrographic seizures during their admission as determined by EEG. The majority (59\%) of all patients had an abnormal EEG, including electrographic seizures $(n=5)$, occasional bursts of generalized rhythmic delta activity $(n=2)$, generalized periodic discharges $(n=2)$, periodic lateralized epileptiform discharges $(n=2)$, periodic sharp waves $(n=4)$, and patterns typical of encephalopathy including diffuse delta and theta frequency slowing $(\mathrm{n}=12)$. 
Table 1 Demographics, clinical characteristics, laboratory data, and outcomes in patients with Eastern equine encephalitis

\begin{tabular}{|c|c|c|c|}
\hline & Overall prevalence $(n=17)$ & Received IVIG $(n=11)$ & Did not receive IVIG $(n=6)$ \\
\hline \multicolumn{4}{|l|}{ Demographics } \\
\hline Age, years (median [IQR]) & $63[36-70]$ & $63[52-72]$ & $44[22-61]$ \\
\hline \multicolumn{4}{|l|}{ Race, n (\%) } \\
\hline White & $16(94)$ & $11(100)$ & $5(83)$ \\
\hline Hispanic & $1(6)$ & $0(0)$ & $1(6)$ \\
\hline \multicolumn{4}{|l|}{ Sex, n (\%) } \\
\hline Male & $10(59)$ & $6(55)$ & $4(67)$ \\
\hline Female & $7(41)$ & $5(46)$ & $2(33)$ \\
\hline \multicolumn{4}{|l|}{ Clinical characteristics (n (\%)) } \\
\hline Fever & $17(100)$ & $11(100)$ & $6(100)$ \\
\hline Altered mental status & $15(88)$ & $10(91)$ & $5(83)$ \\
\hline Headache & $12(71)$ & $7(64)$ & $5(83)$ \\
\hline Photophobia & $3(18)$ & $1(9)$ & $2(33)$ \\
\hline Neck stiffness & $3(18)$ & $2(18)$ & $1(17)$ \\
\hline Nausea & $5(29)$ & $2(18)$ & $3(50)$ \\
\hline Vomiting & $6(35)$ & $2(18)$ & $4(67)$ \\
\hline Abdominal pain & $3(18)$ & $0(0)$ & $3(50)$ \\
\hline Respiratory symptoms & $2(12)$ & $1(9)$ & $1(17)$ \\
\hline Tremor & $6(35)$ & $6(55)$ & $0(0)$ \\
\hline Seizures & $7(41)$ & $5(46)$ & $2(33)$ \\
\hline Abnormal EEG & $10(59)$ & $7(64)$ & $3(50)$ \\
\hline Prodrome, days, mean (range) & $3(0-9)$ & $3(0-7)$ & $3(0-9)$ \\
\hline \multicolumn{4}{|c|}{ Laboratory characteristics (median [IQR]) } \\
\hline CSF WBC, cells, uL & 369 [185-831] & $369[177-860]$ & $529[171-1,152]$ \\
\hline CSF glucose, mg/dL & 65 [57-78] & $65[55-79]$ & 66 [58-92] \\
\hline CSF total protein, $\mathrm{mg} / \mathrm{dL}$ & $100[75-145]$ & 113 [80-149] & $80[73-152]$ \\
\hline Serum WBC, K/uL & $13[8-16]$ & $13[7-16]$ & $11[9-17]$ \\
\hline Sodium, $\mathrm{mmol} / \mathrm{L}$ & 135 [133-138] & 135 [132-138] & 136 [134-139] \\
\hline Platelets, K/uL & $187[158-236]$ & $171[142-217]$ & 215 [174-252] \\
\hline ALT, U/L & $22[16-57]$ & $22[19-57]$ & 18 [13-137] \\
\hline AST, U/L & $36[19-70]$ & 26 [24-73] & $37[11-68]$ \\
\hline Alk Phos, U/L & $59[50-68]$ & $62[45-69]$ & 54 [49-77] \\
\hline \multicolumn{4}{|c|}{ Length of stay, days (median (range)) } \\
\hline Hospital LOS & $18(5-38)$ & $18(6-38)$ & $16(5-35)$ \\
\hline ICU LOS & $10(0-34)$ & $12(1-34)$ & $5(0-14)$ \\
\hline \multicolumn{4}{|l|}{ Outcomes, n (\%) } \\
\hline Survival & $15(88)$ & $9(82)$ & $6(100)$ \\
\hline Death & $2(12)$ & $2(18)$ & $0(0)$ \\
\hline
\end{tabular}


Table 1 Demographics, clinical characteristics, laboratory data, and outcomes in patients with Eastern equine encephalitis (continued)

\begin{tabular}{lcc}
\hline & Overall prevalence $(n=17)$ & Received IVIG $(n=11)$ \\
\hline mRS, median (range) & & Did not receive IVIG $(n=6)$ \\
\hline Admission mRS & $4(1-5)$ & $4(1-5)$ \\
\hline Discharge mRS & $4(1-6)$ & $4(1-5)$ \\
\hline Follow-up mRS & $3(0-6)$ & $4(1-6)$ \\
\hline
\end{tabular}

Abbreviations: ALT = alanine aminotransferase; $\mathrm{AST}=$ aspartate transaminase; $\mathrm{EEE}=$ Eastern equine encephalitis; ICU = intensive care unit; IVIG = IV immunoglobulin; LOS = length of stay; $\mathrm{mRS}=$ modified Rankin Scale; WBC = white blood cell.

Demographic data were collected for all patients with confirmed EEE. Altered mental status included any description of encephalopathy, confusion, or difficulty with attention. Seizures were defined as clinical events with a high degree of suspicion to be true seizures and were entirely comprised of generalized tonic-clonic seizures. High-dose steroids included methylprednisolone and dexamethasone. The typical dose used in the treatment of adult patients was $0.4 \mathrm{~g}$ of IVIG per kilogram of patient body weight for a duration of 5 days; 1 adult patient received $1 \mathrm{~g} / \mathrm{kg}$ IVIG for 2 days. One pediatric case (case 13) received an initial loading dose of $2 \mathrm{~g} / \mathrm{kg}$ IVIG for 1 day, followed by 1 day of $0.5 \mathrm{mg} / \mathrm{kg}$, and the dose was not reported in the other case (case 16 ).

\section{IV immunoglobulin and high-dose steroids}

Of the patients in this cohort, $65 \%(\mathrm{n}=11)$ received IVIG as part of their treatment plan for EEE (table 1). The average time to IVIG treatment was 5 days (range 2-8 days), and the average time to steroid treatment was 7 days (range 3-27 days). Approximately half of patients $(\mathrm{n}=6 ; 35 \%)$ who received IVIG also received high-dose steroids, and $12 \%(\mathrm{n}=2)$ received steroids alone.

\section{Outcomes}

The overall mortality in patients with EEE in this study during hospitalization was $12 \%$ (table 1), lower than historical reports. ${ }^{4,6,8}$ Twelve of the 15 patients who survived EEE had available follow-up clinical data. The median follow-up time was 138 days after initial presentation (range 14-1,586 days). No patients had a reported disability before symptom onset.

Figure 1 Laboratory characteristics: CSF and serum studies in patients with Eastern equine encephalitis

A. CSF WBC

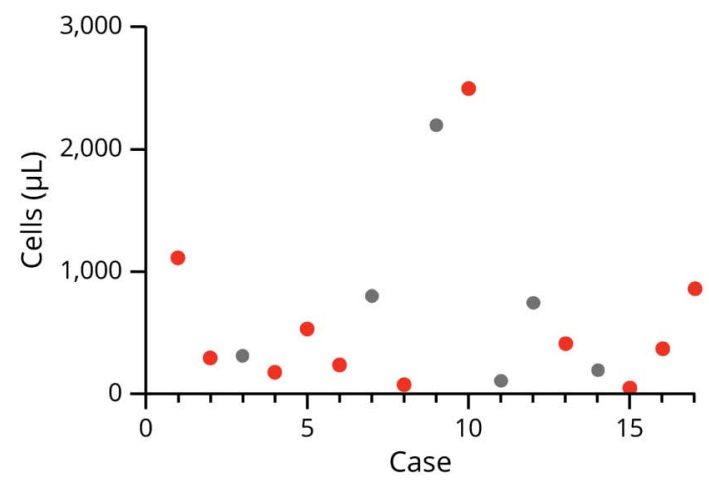

C. CSF glucose

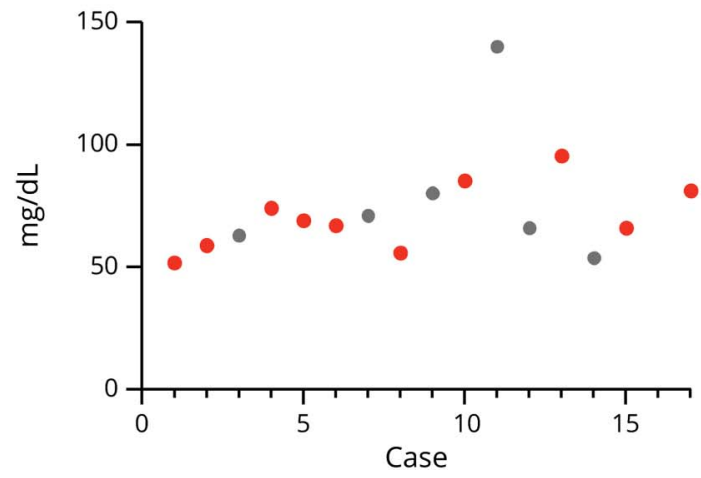

B. CSF protein

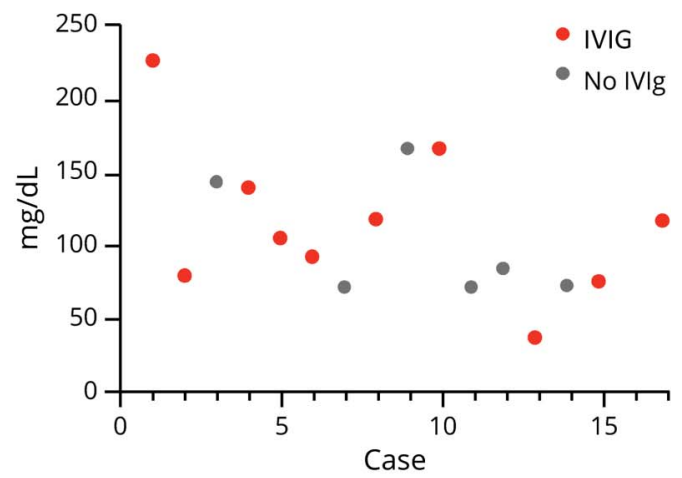

D. CSF WBC differential

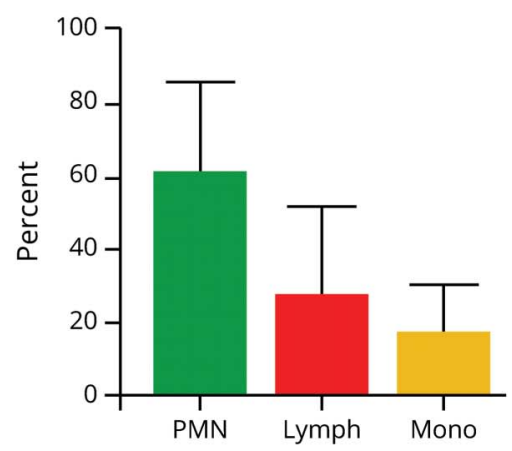

Case number vs units of white blood cells (A), protein (B), and glucose (C) in the CSF of patients with EEE. CSF WBC differential (D) for patients with EEE with available data. $\mathrm{EEE}=$ Eastern equine encephalitis. 
Figure 2 Imaging characteristics: typical pattern of MRI involvement and affected neuroanatomic regions in patients with Eastern equine encephalitis

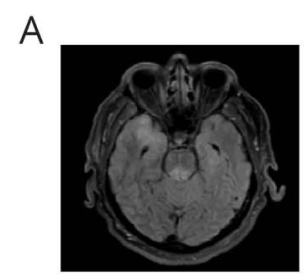

Temporal lobe/pons

$\mathrm{B}$

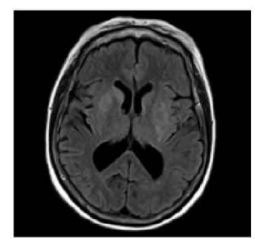

Mild (mRS 0-2)

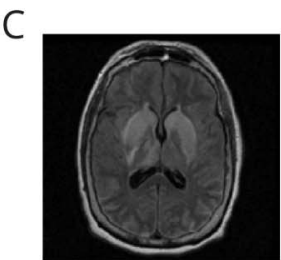

Day 1

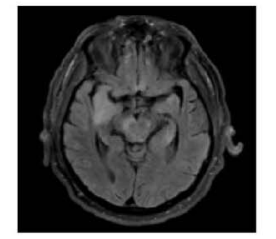

Temporal lobe/midbrain

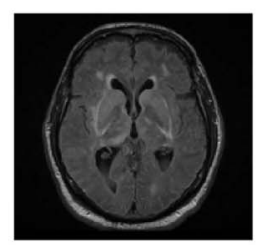

Moderate (mRS 3-4)

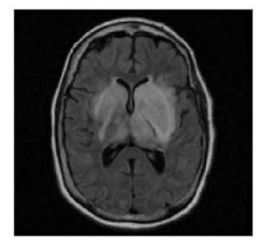

Day 4

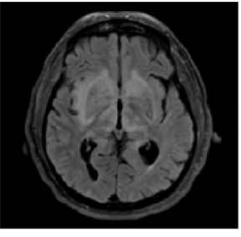

Basal ganglia

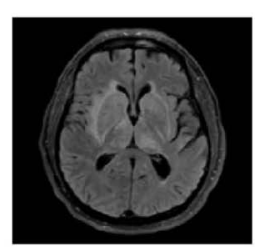

Severe (mRS 5-6)

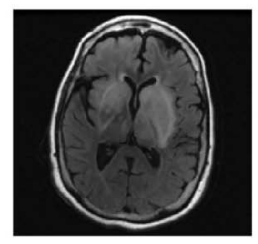

Day 10
D. Neuroanatomic regions
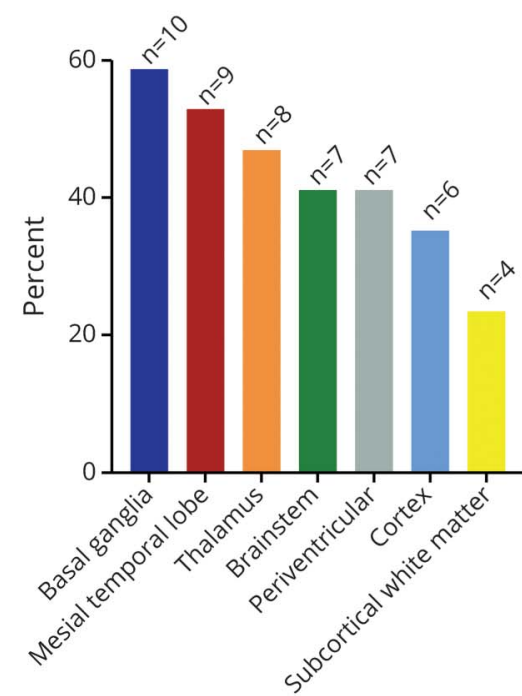

All images displayed are the T2-FLAIR sequence. (A) Representative images of pattern of typical neuroanatomic region involved in 1 patient with demonstrated involvement of the temporal lobe and pons, temporal lobe and midbrain, and basal ganglia by T2-FLAIR hyperintensity (panels left to right). (B) Representative images of patients with mild (mRS 0-2), moderate (mRS 3-4), and severe (mRS 5-6) disability score at discharge. (C) Representative images of 1 patient over course of hospitalization at days 1, 4, and 10 after admission. (D) Quantification of neuroanatomic region involvement in initial MRI of patients with EEE as determined by T2-FLAIR hyperintensity. An area was scored as abnormal only once per patient. EEE = Eastern equine encephalitis.

On average, patients presented to the hospital with moderately severe disability ( $\mathrm{mRS} 3.8$ ) and were discharged without a clinically meaningful change in scores (mRS 3.6) (figure $3 A)$. Seventy-one percent of patients $(n=12)$ were discharged to an acute inpatient rehabilitation center, 1 patient who was immunosuppressed (6\%) died while hospitalized, 1 patient $(6 \%)$ was discharged to hospice care and died, and the remainder $(\mathrm{n}=3 ; 18 \%)$ were discharged home without requiring any at-home services. Among those with available follow-up by chart review, there was a reduction in the median mRS compared with discharge $\mathrm{mRS}$ (follow-up $\mathrm{mRS} 3, \mathrm{IQR}=$ $0-6$ vs discharge $\mathrm{mRS} 4, \mathrm{IQR}=1-6$ ) (figure $3 \mathrm{~A}$ ). Long-term management with antiepileptic drugs (AEDs) at follow-up was necessary in 2 of 3 children (67\%) and no adult patients.

We were interested to determine whether there was a correlation between discharge or follow-up mRS and time to IVIG administration among treated individuals (figure 3, B and C). Admission mRS before treatment did not correlate with time to IVIG administration, indicating that the severity of neurologic disease did not affect the time to IVIG initiation (figure e-2A, links.lww. com/NXI/A348), and the median baseline mRS among patients who received IVIG and those who did not receive IVIG was similar. In contrast, time to IVIG administration correlated with mRS scores at discharge and follow-up (figure 3, B and C). This trend held true when the immunocompromised patient was excluded. There was no correlation between admission, discharge, or follow-up mRS and time to steroid administration (figure e-2, links.lww.com/NXI/A348). Six patients did not receive immunomodulatory therapy, making comparisons between IVIG and standard of care challenging.

Although the overall number of patients is not large enough to determine a clear relationship between radiographic findings and disability score, patients with more neuroanatomic regions affected at presentation tended to have worse disability at discharge and follow-up (figure e-3, links.lww.com/NXI/A348). Outliers include the patient (case 5) who had an unremarkable MRI at presentation, was on rituximab, and ultimately died. The patient (case 16) with 4 neuroanatomic regions affected and admission mRS 4 had low follow-up mRS 1 and was a pediatric case.

Follow-up clinical visits for patients who survived EEE were reviewed to understand the long-term disability among survivors and the typical pattern of disability. Patients with ongoing disability at follow-up (11/12 with available data) commonly had clinical evidence of cognitive or memory impairment, increased muscle tone in the extremities, and spasticity. Thirty-three percent $(n=4)$ had difficulty in language, ranging from decreased spontaneous speech to global 

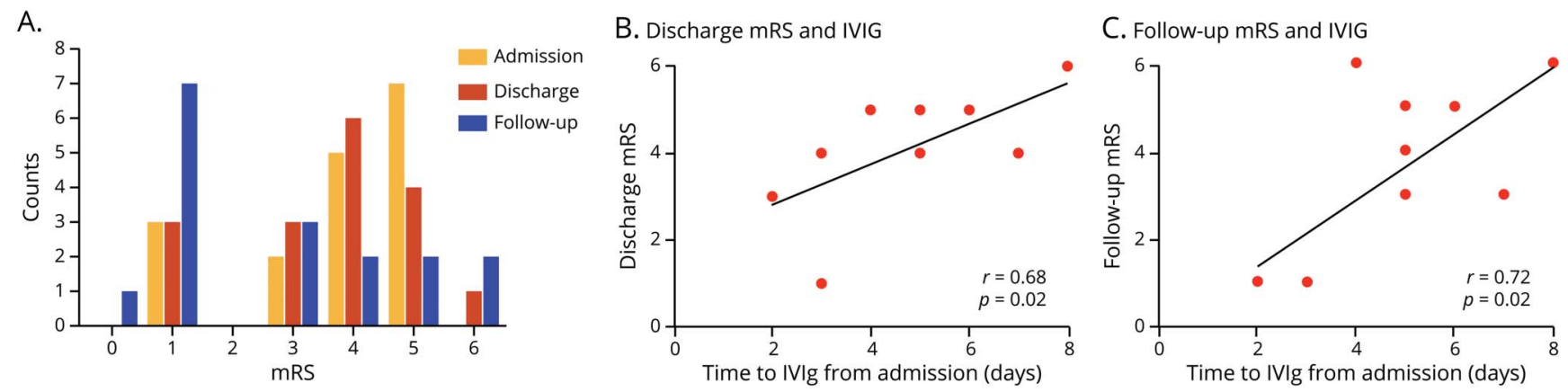

Patient disability by modified Rankin Scale (mRS) of patients with EEE at admission to the hospital, discharge from the hospital, and last recorded follow-up (A). Time to IVIG administration compared with mRS at discharge (B) and most recent clinical follow-up (C). Comparative studies were performed using a Spearman rho and a $p$ value with a 2-tailed distribution. EEE = Eastern equine encephalitis; IVIG = IV immunoglobulin.

aphasia with no language understanding or production. Eight patients $(67 \%)$ regained ability to participate in the activities of daily living. Only 1 patient (case 12) with an admission mRS of 1 had no disability at follow-up. It is difficult to be certain if IVIG had any impact on the natural history of EEE as only 8 patients were in the treatment group and there is no matched control group by age or severity of illness.

\section{Discussion}

This study is a case series detailing clinical, laboratory, radiographic, and patient outcomes with use of IVIG for offlabel treatment of EEE. The overall mortality in this population was $12 \%$, compared with past studies, which estimated the mortality from EEE to be approximately $40 \%$, including a prior case series from New England. ${ }^{8}$ This difference in mortality is likely multifactorial, including improvements in standard care modalities and possibly increased EEE CSF testing to identify less severe cases.

The clinical presentation and epidemiology of EEE patients in this study closely reflects prior studies, with a presentation characterized by fever, headache, and encephalopathy in an endemic region. ${ }^{1,4,8}$ No cases presented later than mid-September, and patients had a maximum prodrome length of 9 days, an important consideration when evaluating patients for possible EEE. The seasonal timeline of cases is also consistent with the Massachusetts Department of Public Health mosquito surveillance data, with the latest EEE positive mosquito vector on October 3 in the most recent 2019 outbreak. $^{28}$ Unlike some opportunistic viral CNS infections, including cytomegalovirus, human herpes virus 6, and JC virus, the majority of EEE patients were healthy immunocompetent adults, and only 1 patient in this study was immunocompromised. The age distribution of EEE cases was bimodal with a cluster of pediatric cases and most adult cases occurring in patients older than 60 years. This possibly reflects age-dependent changes in the CNS immune response leading to increased susceptibility and severity of disease in children and older adults. ${ }^{29-31}$
Unlike other viral encephalitides typically characterized by a lymphocytic predominance in the $\mathrm{CSF}^{32}$ including herpesviruses and enteroviruses, the majority (79\%) of patients with EEE had an initial neutrophilic predominance, consistent with prior studies. ${ }^{33}$ These data reflect preclinical models and pathologic studies of $\mathrm{EEE}^{34,35}$ and suggest that patients have a robust early neutrophilic innate immune response to EEEV, which later develops into a lymphocyte-predominant adaptive response. Why some viruses initiate a neutrophilic response early in infection while others are lymphocyte predominant is likely the result of multiple complex host-pathogen interactions, including viral evasion of the early innate response, generation of pathogen-specific $\mathrm{T}$ cells, and correlation between a patient's clinical presentation and viral replication in the brain. ${ }^{36,37}$

The neuroanatomic distribution of EEE pathology seen on MRI reflects a viral predilection for the basal ganglia, thalamus, and mesial temporal lobe. Although other etiologies of viral encephalitis affect the mesial temporal lobe, namely HSV encephalitis, ${ }^{38}$ EEEV also has characteristic involvement of deep basal ganglia and thalamic structures. ${ }^{8}$ Of interest, children in this study had more cortical involvement compared with adults, which was also seen in a large review of pediatric cases. ${ }^{9}$ Preclinical studies in other CNS arboviral infections suggest that tropism may be driven by region-dependent immune responses resulting in differential susceptibility within the brain. ${ }^{39}$ Although there are no standardized MRI scoring systems for CNS infections, comparing the MRI at admission to the long-term disability score, there is a trend toward more neuroanatomic regions involved relating to worse disability at follow-up.

The theoretical benefit from IVIG is thought to be due to antibody neutralization of virus particles and IgG suppression of immune function. The influence of IVIG on the immune response may occur partly through inhibition of macrophage activity, disruption of T-cell interactions with antigen-presenting cells, and downregulation of B-cell proliferation and endogenous 
antibody production. ${ }^{40}$ Although there was a positive correlation between time to IVIG administration and disability score at follow-up, which could suggest that early IVIG administration decreases long-term disability, we interpret these data with caution. Conclusions regarding the utility of IVIG in the treatment of EEE are limited by the relatively small size of the sample population and inability to control for relevant patient factors including age, sex, and disease severity. At this time, it is only speculative that earlier initiation of IVIG may be associated with a reduction in disability and would require a prospective study or clinical trial. High-dose steroids did not correlate with disability in this study.

Of interest, all patients with the exception of case 4 (adult) and case 5 (immunosuppressed) had improvement in their $\mathrm{mRS}$ between admission and follow-up, regardless of steroid and IVIG intervention. In addition, these data demonstrate that despite almost half of patients with EEE experiencing seizures at presentation or during admission, no adult patients went on to require long-term management with AEDs. This may be related to the primarily basal ganglia and thalamic location of pathology in EEE compared with other etiologies of viral encephalitis, such as herpes simplex virus, which typically have cortical involvement and high rates of postviral epilepsy. ${ }^{41}$ In contrast to adults with EEE, children in this study had higher rates of cortical involvement, and the majority (67\%) required long-term management with AEDs.

This study is limited by its retrospective nature and reliance on electronic medical record for the collection of data throughout the disease course. Patients were not randomized to receive IVIG or steroids, and the factors that went into treatment decisions were not clear in the medical notes. The study is also limited by the small number of patients, which is driven by the rarity of EEE resulting in neurologic complications requiring hospitalization, typically considered to be approximately $5 \%$ of all people infected with EEEV. It is likely that as testing becomes more frequent, there will be a larger portion of mildly symptomatic and asymptomatic patients identified, similar to other arboviral infections including $\mathrm{WNV}^{42}$ Of interest, the mortality rate in our study was low (12\%) despite most patients being transferred to tertiary hospitals for advanced care, which typically occurs in more severe cases, and can constitute referral bias. Although a prospective study of EEE with larger samples sizes would reduce some of these limitations, the rarity of this disease makes prospective studies challenging to perform.

This study, despite the challenges with its retrospective nature, suggests that any immunomodulator trials will need to consider early intervention in trial designs and possibly be aided by biomarkers such as neuroimaging. Irrespective of intervention, there was minimal change from admission mRS to discharge $\mathrm{mRS}$ in immunocompetent adults, which suggests that preventive measures to reduce EEEV transmission will provide the most benefit in endemic areas in the absence of an effective vaccine or targeted antiviral therapy.

\section{Study funding}

S.S. Mukerji and S.I. Collens were funded by the National Institute of Mental Heath at the National Institutes of Health (grant No. K23MH115812).

\section{Disclosure}

The authors report no disclosures. Go to Neurology.org/NN for full disclosures.

\section{Publication history}

Received by Neurology: Neuroimmunology \& Neuroinflammation September 3, 2020. Accepted in final form September 28, 2020.

Appendix Authors

\begin{tabular}{lll}
\hline Name & Location & Contribution \\
\hline $\begin{array}{l}\text { Douglas R. } \\
\text { Wilcox, } \\
\text { MD, PhD }\end{array}$ & $\begin{array}{l}\text { Brigham and Women's } \\
\text { Hospital, Massachusetts } \\
\text { General Hospital, Boston }\end{array}$ & $\begin{array}{l}\text { Designed and } \\
\text { conceptualized the study; } \\
\text { analyzed the data; } \\
\text { interpreted the data; and } \\
\text { drafted the manuscript for } \\
\text { intellectual content }\end{array}$ \\
\hline $\begin{array}{l}\text { Sarah I. } \\
\text { Collens, BS }\end{array}$ & $\begin{array}{l}\text { Massachusetts General } \\
\text { Hospital, Boston }\end{array}$ & $\begin{array}{l}\text { Major role in the } \\
\text { acquisition of data and } \\
\text { analyzed the data }\end{array}$ \\
\hline $\begin{array}{l}\text { Isaac H. } \\
\text { Solomon, } \\
\text { MD, PhD }\end{array}$ & $\begin{array}{l}\text { Brigham and Women's } \\
\text { Hospital, Boston }\end{array}$ & $\begin{array}{l}\text { Interpreted the data and } \\
\text { revised the manuscript for } \\
\text { intellectual content }\end{array}$ \\
\hline $\begin{array}{l}\text { Farrah J. } \\
\text { Mateen, } \\
\text { MD, PhD }\end{array}$ & $\begin{array}{l}\text { Massachusetts General } \\
\text { Hospital, Boston }\end{array}$ & $\begin{array}{l}\text { Analyzed the data; } \\
\text { interpreted the data; and } \\
\text { revised the manuscript for } \\
\text { intellectual content }\end{array}$ \\
\hline $\begin{array}{l}\text { Shibani S. } \\
\text { Mukerji, }\end{array}$ & $\begin{array}{l}\text { Massachusetts General } \\
\text { Hospital, Boston }\end{array}$ & $\begin{array}{l}\text { Analyzed the data; } \\
\text { interpreted the data; and } \\
\text { revised the manuscript for } \\
\text { intellectual content }\end{array}$ \\
\hline
\end{tabular}

\section{References}

1. Morens DM, Folkers GK, Fauci AS. Eastern equine encephalitis virus-another emergent arbovirus in the United States. N Engl J Med 2019;381:1989-1992.

2. Fothergill LD, Dingle JH, Farber S, Connerley ML. Human encephalitis caused by the virus of the eastern variety of equine encephalomyelitis. N Engl J Med 1938;219:411.

3. Armstrong PM, Andreadis TG. Eastern equine encephalitis virus-old enemy, new threat. N Engl J Med 2013;368:1670-1673.

4. Lindsey NP, Staples JE, Fischer M. Eastern equine encephalitis virus in the United States, 2003-2016. Am J Trop Med Hyg 2018;98:1472-1477.

5. Monath TP. Arthropod-borne encephalitides in the Americas. Bull World Health Organ 1979;57:513-533.

6. Feemster RF. Equine encephalitis in Massachusetts. N Engl J Med 1957;257: 701-704.

7. Goldfield M, Welsh JN, Taylor BF. The 1959 outbreak of eastern encephalitis in New Jersey: 5. The inapparent infection: disease ratio. Am J Epidemiol 1968;87:32-38.

8. Deresiewicz RL, Thaler SJ, Hsu L, Zamani AA. Clinical and neuroradiographic manifestations of eastern equine encephalitis. N Engl J Med 1997;336:1867-1874.

9. Silverman MA, Misasi J, Smole S, et al. Eastern equine encephalitis in children, Massachusetts and New Hampshire, USA, 1970-2010. Emerg Infect Dis 2013;19: 194-352.

10. Getting VA. Equine encephalomyelitis in Massachusetts. N Engl J Med 1941;224: 999-1006.

11. Winston DJ, Vikram HR, Rabe IB, et al. Donor-derived West Nile virus infection in solid organ transplant recipients: report of four additional cases and review of clinical, diagnostic, and therapeutic features. Transplantation 2014;97:881-889.

12. Rayamajhi A, Nightingale S, Bhatta NK, et al. A preliminary randomized double blind placebo-controlled trial of intravenous immunoglobulin for Japanese encephalitis in Nepal. PLoS One 2015;10:e122608.

13. Hartmann CA, Vikram HR, Seville MT, et al. Neuroinvasive St. Louis encephalitis virus infection in solid organ transplant recipients. Am J Transpl 2017;17:2200-2206. 
14. Tunkel AR, Glaser CA, Bloch KC, et al. The management of encephalitis: clinical practice guidelines by the Infectious Diseases Society of America. Clin Infect Dis 2008;47:303-327.

15. Mukerji SS, Lam AD, Wilson MR. Eastern equine encephalitis treated with intravenous immunoglobulins. Neurohospitalist 2016;6:29-31.

16. Golomb MR, Durand M, Schaefer PW, McDonald CT, Maia M, Schwamm LH. A case of immunotherapy-responsive eastern equine encephalitis with diffusionweighted imaging. Neurology 2001;56:420-421.

17. Wendell LC, Stevenson Potter N, Roth JL, Salloway SP, Thompson BB. Successful management of severe neuroinvasive eastern equine encephalitis. Neurocrit Care 2013;19:111-115.

18. Erkkinen M, Srikanth M, Lyons J, Vaitkevicius H. Successful treatment of eastern equine encephalitis with early, empiric initiation of intravenous immunoglobulin: a case report (P6.306). Neurology 2015;84:P6.306.

19. Makhoul B, Braun E, Herskovitz M, Ramadan R, Hadad S, Norberto K. Hyperimmune gammaglobulin for the treatment of West Nile virus encephalitis. Isr Med Assoc J 2009;11:151-153.

20. Haley M, Retter AS, Fowler D, Gea-Banacloche J, O'Grady NP. The role for intravenous immunoglobulin in the treatment of West Nile virus encephalitis. Clin Infect Dis 2003;37:e88-90.

21. Smole SC. Manual of Laboratory Tests and Services. In: HEALTH DOP, ed, 7th ed.Boston, MA: Massachusetts Department of Public Health Bureau of Infectious Disease and Laboratory Sciences; 2018.

22. Johnson AJ, Martin DA, Karabatsos N, Roehrig JT. Detection of anti-arboviral immunoglobulin $\mathrm{G}$ by using a monoclonal antibody-based capture enzyme-linked immunosorbent assay. J Clin Microbiol 2000;38:1827-1831.

23. van Swieten JC, Koudstaal PJ, Visser MC, Schouten HJ, van Gijn J. Interobserver agreement for the assessment of handicap in stroke patients. Stroke 1988;19:604-607.

24. Nakano A, Yamasaki R, Miyazaki S, Horiuchi N, Kunishige M, Mitsui T. Beneficial effect of steroid pulse therapy on acute viral encephalitis. Eur Neurol 2003;50:225-229.

25. Hoke CH Jr, Vaughn DW, Nisalak A, et al. Effect of high-dose dexamethasone on the outcome of acute encephalitis due to Japanese encephalitis virus. J Infect Dis 1992; 165:631-637.

26. R: A Language and Environment for Statistical Computing [computer program]. Vienna, Austria: R Foundation for Statistical Computing; 2019.

27. Solomon IH, Ciarlini PDSC, Santagata S, et al. Fatal eastern equine encephalitis in a patient on maintenance rituximab: a case report. Open Forum Infect Dis 2017;4:ofx021.
28. Sciences MDoPHBoIDaL. 2019 Massachusetts Arbovirus Daily Update: Mosquito Samples Positive [online]. Available at: mosquitoresults.com/mosquitos-positive/. Accessed May 10, 2020.

29. Morgan IM. Influence of age on susceptibility and on immune response of mice to eastern equine encephalomyelitis virus. J Exp Med 1941;74:115-132.

30. Wilcox DR, Folmsbee SS, Muller WJ, Longnecker R. The type I interferon response determines differences in choroid plexus susceptibility between newborns and adults in herpes simplex virus encephalitis. MBio 2016;7:e00437-00416.

31. Wilcox DR, Wadhwani NR, Longnecker R, Muller WJ. Differential reliance on autophagy for protection from HSV encephalitis between newborns and adults. PLoS Pathog 2015;11:e1004580.

32. Jaijakul S, Salazar L, Wootton SH, Aguilera E, Hasbun R. The clinical significance of neutrophilic pleocytosis in cerebrospinal fluid in patients with viral central nervous system infections. Int J Infect Dis 2017;59:77-81.

33. Przelomski MM, O’Rourke E, Grady GF, Berardi VP, Markley HG. Eastern equine encephalitis in Massachusetts: a report of 16 cases, 1970-1984. Neurology 1988;38:736-739.

34. Farber S, Hill A, Connerly ML, Dingle JH. Encephalitis in infants and children: caused by the virus of the eastern variety of equine encephalitis. J Am Med Assoc 1940;114: $1725-1731$.

35. Vogel P, Kell WM, Fritz DL, Parker MD, Schoepp RJ. Early events in the pathogenesis of eastern equine encephalitis virus in mice. Am J Pathol 2005;166:159-171.

36. Lopez-Cortes LF, Cruz-Ruiz M, Gomez-Mateos J, Viciana-Fernandez P, MartinezMarcos FJ, Pachon J. Interleukin-8 in cerebrospinal fluid from patients with meningitis of different etiologies: its possible role as neutrophil chemotactic factor. J Infect Dis $1995 ; 172: 581-584$

37. Richner JM, Gmyrek GB, Govero J, et al. Age-dependent cell trafficking defects in draining lymph nodes impair adaptive immunity and control of West Nile virus infection. PLoS Pathog 2013;11:e1005027.

38. Tyler KL. Acute viral encephalitis. N Engl J Med 2018;379:557-566.

39. Daniels BP, Jujjavarapu H, Durrant DM, et al. Regional astrocyte IFN signaling restricts pathogenesis during neurotropic viral infection. J Clin Invest 2017;127: 843-856.

40. Hartung HP. Advances in the understanding of the mechanism of action of IVIg. J Neurol 2008;255(suppl 3):3-6.

41. Sellner J, Trinka E. Seizures and epilepsy in herpes simplex virus encephalitis: current concepts and future directions of pathogenesis and management. J Neurol 2012;259: 2019-2030.

42. Petersen LR. Epidemiology of West Nile virus in the United States: implications for arbovirology and public Health. J Med Entomol 2019;56:1456-1462. 


\title{
Neurology ${ }^{\oplus}$ \\ Neuroimmunology \& Neuroinflammation
}

\author{
Eastern equine encephalitis and use of IV immunoglobulin therapy and high-dose \\ steroids \\ Douglas R. Wilcox, Sarah I. Collens, Isaac H. Solomon, et al. \\ Neurol Neuroimmunol Neuroinflamm 2021;8; \\ DOI 10.1212/NXI.0000000000000917
}

This information is current as of November 10, 2020

Neurol Neuroimmunol Neuroinflamm is an official journal of the American Academy of Neurology.

Published since April 2014, it is an open-access, online-only, continuous publication journal. Copyright

Copyright $\odot 2020$ The Author(s). Published by Wolters Kluwer Health, Inc. on behalf of the American

Academy of Neurology.. All rights reserved. Online ISSN: 2332-7812.

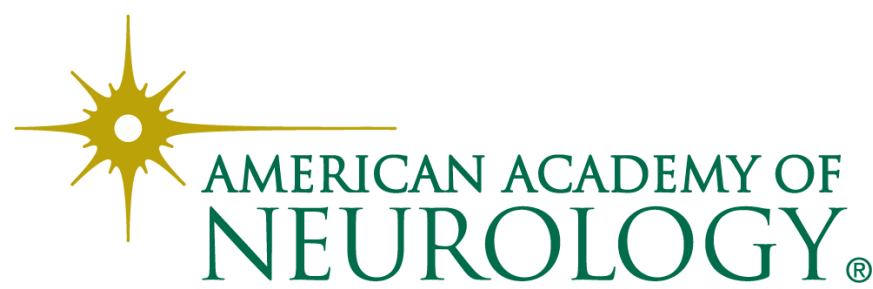




\section{Updated Information \& Services}

References

Subspecialty Collections

Permissions \& Licensing

Reprints including high resolution figures, can be found at: http://nn.neurology.org/content/8/1/e917.full.html

This article cites 39 articles, 3 of which you can access for free at: http://nn.neurology.org/content/8/1/e917.full.html\#\#ref-list-1

This article, along with others on similar topics, appears in the following collection(s):

\section{EEG}

http://nn.neurology.org//cgi/collection/eeg_

Encephalitis

http://nn.neurology.org//cgi/collection/encephalitis

MRI

http://nn.neurology.org//cgi/collection/mri

Natural history studies (prognosis)

http://nn.neurology.org//cgi/collection/natural_history_studies_prognos is

Viral infections

http://nn.neurology.org//cgi/collection/viral_infections

Information about reproducing this article in parts (figures,tables) or in its entirety can be found online at:

http://nn.neurology.org/misc/about.xhtml\#permissions

Information about ordering reprints can be found online:

http://nn.neurology.org/misc/addir.xhtml\#reprintsus

Neurol Neuroimmunol Neuroinflamm is an official journal of the American Academy of Neurology.

Published since April 2014, it is an open-access, online-only, continuous publication journal. Copyright

Copyright $\odot 2020$ The Author(s). Published by Wolters Kluwer Health, Inc. on behalf of the American Academy of Neurology.. All rights reserved. Online ISSN: 2332-7812.

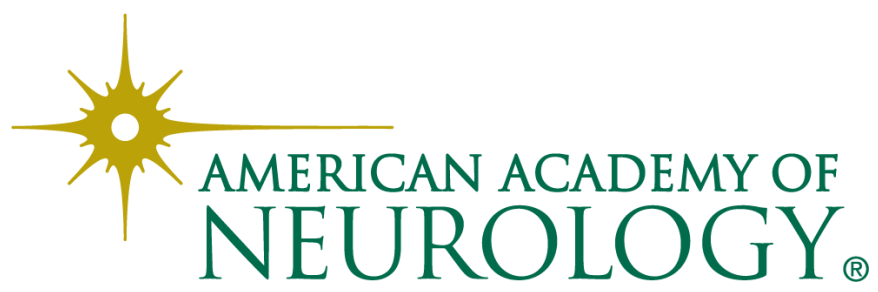

